\title{
Consumo de alimentos dos grupos que compõem a pirâmide alimentar americana por idosos brasileiros: uma revisão
}

\author{
Food intake of the groups part of the American food pyramid by Brazilian elderly: a review
}

\author{
Rúbia Garcia Deon ${ }^{a}$, Rosane Dias da Rosab ${ }^{b}$ Vivian Polachini Skzypek Zanardoc, Vera Elizabeth Closs ${ }^{d}$, \\ Carla Helena Augustin Schwanke \\ a Nutricionista. Doutoranda do Programa de Pós-Graduação em Gerontologia Biomédica do Instituto de Geriatria e Gerontologia (IGG) da Pontifícia Universidade Católica \\ do Rio Grande do Sul (PUCRS). Professora da Universidade Integrada do Alto Uruguai e das Missões (URI), Campus Frederico Westphalen/RS. \\ b Nutricionista. Doutoranda do Programa de Pós-Graduação em Gerontologia Biomédica (IGG/PUCRS). \\ c Nutricionista. Doutoranda do Programa de Pós-Graduação em Gerontologia Biomédica (IGG/PUCRS). Professora da Universidade Integrada do Alto Uruguai e \\ das Missões (URI) - Campus Erechim/RS.

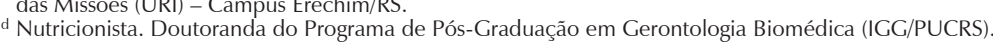 \\ e Médica geriatra. Doutora em Gerontologia Biomédica. Professora permanente do Programa de Pós-graduação em Gerontologia Biomédica (IGG/PUCRS). \\ Coordenadora do Grupo de Estudos em Risco Cardiometabólico, Envelhecimento e Nutrição (GERICEN-CNPq).
}

Fontes de financiamento: CAPES e PROSUP-PUCRS (bolsas de estudo).

RESUMO

Introdução: A pirâmide alimentar adaptada para a população idosa americana é um guia alimentar que destaca a importância da alimentação equilibrada para o envelhecimento bem sucedido.

Objetivo: Apresentar uma revisão literária sobre as evidências do consumo de alimentos dos grupos que compõem a pirâmide alimentar americana por idosos brasileiros.

Materiais e Métodos: Foram incluídos artigos científicos (identificados no LILACS e Medline/PubMed), dissertações e teses (identificadas no portal da CAPES), relatórios técnico-científicos, guias e livros. Os termos de busca e operadores boleanos utilizados foram: ("guias alimentares" ou "consumo de alimentos" ou "nutrição") E ("idoso" ou "envelhecimento") e seus correlatos em inglês, publicados entre 2000-2014, envolvendo seres humanos.

Resultados: Em idosos brasileiros de diferentes contextos e de diferentes regiões, o consumo de alimentos pertencentes a oito dos nove grupos da pirâmide adaptada para a população idosa americana (cereais/pães/tubérculos/raízes, hortaliças, frutas, leguminosas, leite/derivados, carnes/ovos, açúcares/doces e água) não é adequado. Somente em relação ao consumo de gorduras e óleos os dados mostraram-se controversos, apontando tanto adequação (em relação ao consumo de colesterol, gordura saturada, ácidos graxos monoinsaturados e ácidos graxos poli-insaturados) quanto inadequação (especialmente em relação ao consumo de ácidos graxos saturados).

Conclusão: As evidências apontam que o consumo, por idosos brasileiros, dos alimentos integrantes dos grupos da pirâmide alimentar adaptada para a população idosa americana, em geral, não está adequado.

Palavras-chave: Guias alimentares. Consumo de alimentos. Nutrição do idoso. Idoso. Envelhecimento.

Introduction: The food pyramid adapted for the American elderly population is a food guide that highlights the importance of balanced diet for successful aging

Objective: To present a literary review on food intake evidence of the groups that are part of the American food pyramid by Brazilian elderly.

Materials and Methods: We included scientific articles (identified in the LILACS and Medline/PubMed), dissertations and theses (identified in the CAPES portal), technical and scientific reports, guides and books. The Boolean operators and search terms used were: ("food guides" or "food consumption" or "nutrition") and ("aged" or "aging"), published between 2000-2014 and involving humans.

Results: In Brazilian elderly from different contexts and different regions, the consumption of food belonging to eight of nine groups of the food pyramid adapted to the American elderly population (grains, breads, tubers, roots, vegetables, fruits, pulses, milk, dairy products, meat, eggs, sugar candies, and water) is not suitable. Only in relation to the consumption of fats and oils the data showed to be controversial, pointing adequacy (in relation to the consumption of cholesterol, saturated fat, mono unsaturated and polyunsaturated fatty acids) and inadequacy (especially in relation to the consumption of saturated fatty acids).

Conclusion: The evidence points that the consumption, by Brazilian elderly, of the food groups of the food pyramid adapted to the American elderly population, in general, is not appropriate.

Keywords: Food guide. Food consumption. Elderly nutrition. Aged. Aging. 


\section{INTRODUÇÃO}

O envelhecimento populacional, antes considerado um fenômeno, hoje faz parte da realidade da maioria das sociedades ${ }^{1}$. Diante disso, cada vez mais se trabalha com a perspectiva de envelhecer pensando na saúde de forma integral ${ }^{2}$.

A alimentação saudável, por sua vez, pode contribuir para a melhora da qualidade de vida e do envelhecimento bem sucedido ${ }^{3}$. A alimentação saudável pode ser definida como: aquela que fornece quantidades adequadas de nutrientes (carboidratos, proteínas, gorduras, vitaminas e minerais); rica em frutas e verduras; moderada em gorduras, sal e açúcar; aquela que proporciona uma boa hidratação e que apresenta um fracionamento entre quatro a seis refeições diárias ${ }^{3}$.

O Ministério da Saúde do Brasil, com o objetivo de oferecer subsídios aos profissionais da saúde, na orientação à pessoa idosa e sua família, publicou os dez passos para uma alimentação saudável para pessoas idosas ${ }^{4}$. Para a população brasileira em geral, o mesmo órgão apresentou, em 2014, a nova versão do Guia Alimentar para a População Brasileira, com o objetivo de apoiar as ações de Educação Alimentar e Nutricional no Sistema Único de Saúde (SUS) ${ }^{5}$.

Na mesma direção, para uma melhor compreensão por parte da população, diversas publicações têm procurado representar a distribuição ideal dos alimentos de uma forma gráfica. Estes guias alimentares, com a distribuição dos grupos de alimentos através de figuras, em diferentes formas e níveis e com o estabelecimento de porções para o consumo, estão fundamentados no hábito e no comportamento alimentar da população ${ }^{6}$. Entre as diversas formas testadas, a pirâmide dos alimentos tem sido amplamente utilizada e se firmado como instrumento de orientação e de educação nutricional à disposição dos nutricionistas, com o objetivo de promover mudanças nos hábitos alimentares visando à saúde global do indivíduo e à prevenção de doenças.

A pirâmide alimentar adaptada para a população idosa americana é um guia alimentar que destaca a importância da alimentação equilibrada para o envelhecimento bem sucedido. Suas recomendações baseiam-se nas necessidades nutricionais desta faixa etária?.

Os grupos alimentares que compõem a referida pirâmide alimentar são assim apresentados: ingestão de líquidos saudáveis como água (no segundo nível da base da pirâmide); cereais/pães/tubérculos/raízes, hortaliças, frutas, leguminosas, leite/derivados, carnes/ovos, açúcares/doces, gorduras/óleos (distribuídos verticalmente, no corpo da pirâmide alimentar), e vitaminas/sais minerais (no topo da pirâmide de alimentos, representado por uma bandeira, que destaca o consumo de cálcio, de vitamina B12 e de vitamina D). Suplementações, como a de cálcio, vitaminas D e B12 são recomendadas, no caso de idoso que não consiga atingir as necessidades destes nutrientes somente com a alimentação ${ }^{7}$. Contudo, esta pirâmide alimentar não se restringe à alimentação e, sim, a um estilo de vida saudável. Por isso, na sua base, estão representadas as atividades de vida diária e enfatizando a atividade física, simbolizando a independência do idoso ${ }^{7}$.

Neste artigo, os autores buscam apresentar uma revisão literária sobre as evidências do consumo de alimentos dos grupos que compõem a pirâmide alimentar americana por idosos brasileiros. Basearam-se na pirâmide adaptada para a população idosa americana, uma vez que não há uma pirâmide brasileira específica, apenas os dez passos para uma alimentação saudável para pessoas idosas ${ }^{4}$.

\section{MATERIAIS E MÉTODOS}

Trata-se de um artigo de revisão literária, para o qual foram selecionados artigos científicos (identificados através das bases de dados LILACS e Medline/PubMed), dissertações e teses (identificadas no portal da CAPES), relatórios científicos e técnicos, guias e livros, além de referências citadas nestas publicações. Os seguintes termos de busca e operadores boleanos foram utilizados: ("guias alimentares" ou "consumo de alimentos" ou "nutrição") E ("idoso" ou“envelhecimento") e seus correlatos em inglês. Foram consideradas publicações que envolviam seres humanos, do período de 2000 a 2014.

\section{RESULTADOS E DISCUSSÃO}

A seguir, os autores apresentam uma revisão literária sobre os grupos de alimentos que compõe a pirâmide alimentar adaptada para a população idosa americana, inicialmente quanto a uma caracterização geral de cada grupo de alimentos e, na sequência, quanto ao padrão de consumo, por idosos brasileiros, de alimentos integrantes de cada um dos grupos que compõem a pirâmide alimentar.

\section{Cereais, pães, tubérculos e raízes}

$\mathrm{Na}$ pirâmide alimentar para idosos americanos é enfatizada a importância do consumo de grãos e cereais integrais porque estes alimentos são fontes de carboidratos complexos, entre outras propriedades ${ }^{7}$. Deste grupo, alimentos como arroz, pão, macarrão, batata e mandioca têm presença expressiva nos domicílios brasileiros ${ }^{8}$. Contudo, aumentar o consumo de cereais e pães integrais pelos idosos é recomendado, mas não é uma tarefa fácil, pois esses alimentos não estão habitualmente presentes na dieta dos brasileiros ${ }^{9}$.

Os idosos devem ser estimulados, sempre que possível, a comer pães e massas elaborados com farinhas integrais, buscando atingir a quantidade de seis porções deste grupo 
por dia, como também recomendado no Guia Alimentar para a População Brasileira $^{8}$ e nos Dez passos para uma alimentação saudável para pessoas idosas ${ }^{10}$.

Em um estudo que analisou a ingestão de nutrientes de idosos brasileiros, com base no inquérito Nacional de Alimentação 2008-2009, constatou-se que o arroz é um dos alimentos que mais contribui para o valor energético total da dieta $^{11}$. Em outro estudo que avaliou a alimentação de idosos de um município da região Sudeste do Brasil, foi verificado que o consumo médio de cereais era insatisfatório ${ }^{12}$.

\section{Hortaliças}

Conforme a Agência Nacional de Vigilância Sanitária $(\text { ANVISA })^{13}$, a hortaliça é uma planta herbácea que pode ser utilizada como alimento, sendo é classificada em verduras e legumes ${ }^{14}$. As hortaliças oferecem uma variedade de cor, o que é salientado na pirâmide adaptada para a população idosa americana, que considera este grupo brilhante e colorido $^{7}$, possuem pouca gordura, baixa caloria e são ricas em fibras alimentares, minerais ${ }^{15}$, antioxidantes e compostos funcionais ${ }^{16}$. No entanto, a urbanização, a industrialização e a globalização têm influência sobre o estado nutricional das pessoas, pois trouxeram modificações no estilo de vida, adoção de dietas inadequadas e redução do consumo de hortaliças ${ }^{15}$.

No Guia Alimentar para a População Brasileira, é recomendado que sejam consumidas pelo menos três porções de hortaliças ao dia ${ }^{8}$. O consumo desses alimentos está intimamente relacionado com o nível de escolaridade e a renda per capita das pessoas ${ }^{17}$. A Pesquisa de Orçamento Familiar (POF) ${ }^{18}$, realizada em 2009-2010, reafirma estes achados, demonstrando que, nas famílias com renda de até $R$ \$ 400,00 por mês, apenas 3,3\% dos gastos com alimentação eram destinados para a aquisição de verduras e legumes. Já nas famílias com renda mensal maior que $\mathrm{R} \$ 4.000,00,12,7 \%$ deste valor era utilizado para a compra desses alimentos ${ }^{15,19}$. Na POF de anos anteriores, já havia sido constatado o baixo consumo de verduras e legumes por idosos, representando aproximadamente um terço da recomendação do Guia Alimentar para a População Brasileira ${ }^{11}$.

Jaime e Monteiro ${ }^{20}$, em um estudo de base populacional que envolveu a avaliação de 5000 indivíduos brasileiros, observaram que menos de um terço $(30,0 \%)$ da população adulta referia o consumo diário de hortaliças. Entre os indivíduos com mais de 65 anos, o consumo de hortaliças foi de $51,5 \%$ entre as mulheres e $39,2 \%$ entre os homens. Os autores apontaram que o consumo de hortaliças foi maior nas áreas urbanas, que aumentava com a idade, relacionava-se à situação sócio-cultural-econômica (escolaridade e número de bens no domicílio) e era independente do sexo.
Outro estudo transversal de base populacional, conduzido na cidade de São Paulo-SP, com idosos de baixa renda, demostrou que $35 \%$ dos indivíduos não consumiam diariamente nenhum tipo de hortaliça/fruta e que $19,8 \%$ consumiam cinco ou mais porções diárias de hortaliças/ frutas. Destaca-se que $45,2 \%$ dos idosos consumiam diariamente hortaliças/frutas, contudo sem atingir o parâmetro recomendado pela Organização Mundial da Saúde $(\mathrm{OMS})^{17}$. Os pesquisadores apontaram que as hortaliças mais consumidas diariamente foram tomate, alface e cenoura ${ }^{17}$.

Em um estudo sobre o tamanho das porções mais frequentemente consumidas e/ou que mais contribuíam para o valor energético de adultos e idosos residentes no município de São Paulo, os pesquisadores verificaram que alface, cebola e tomate eram as hortaliças mais consumidas. Foi salientado que idosos masculinos consumiam porções significativamente maiores de alface. Outro dado interessante refere-se à quantidade ingerida de alface e de tomate ${ }^{21}$. A ingestão média de alface pelos idosos pesquisados por Carlos et al. ${ }^{21}$ foi de 3 a 4 folhas/dia ( 30 g). Já a ingestão média de tomate foi de 2 fatias/dia. Contudo, a quantidade de alface necessária para atingir o tamanho da porção proposta pela pirâmide alimentar brasileira é de 15 folhas (120 g) e a de tomate é de 4 fatias $(80 \mathrm{~g})^{8,22}$.

\section{Frutas}

A ANVISA ${ }^{13}$ define fruta como o produto procedente da frutificação de uma planta, destinado ao consumo, in natura. As frutas são boas fontes de vitaminas, antioxidantes, fibras alimentares e outros componentes com propriedades funcionais ${ }^{16}$. Além disso, são alimentos com baixa densidade de energia, isto é, com poucas calorias em relação ao volume do alimento consumido, o que favorece a manutenção de peso corporal saudável ${ }^{12}$.

O consumo recomendado é de duas a três porções de frutas diariamente ${ }^{8}$. A ingestão da quantidade adequada desses alimentos pode auxiliar na prevenção das doenças crônicas não transmissíveis como as doenças cardiovasculares e alguns tipos de cânceres ${ }^{16}$. Estimativas da Organização PanAmericana da Saúde ${ }^{23}$ advertem que o consumo insuficiente de frutas está entre os dez fatores de risco mais importantes para o desenvolvimento de doenças. Levy-Costa et al. ${ }^{19}$, analisando a disponibilidade domiciliar de alimentos, observaram um consumo insuficiente de frutas em todas as regiões brasileiras associado a condições socioeconômicas desfavoráveis, como baixa escolaridade e baixo poder aquisitivo.

Um fato que deve ser destacado é a tendência de aumento do consumo de frutas com a idade, que pode ser 
interpretada como uma diferença de hábitos alimentares entre as gerações ou também pela maior atenção desse grupo etário em relação à sua saúde ${ }^{17}$.

Fisberg et al. ${ }^{11}$ ao analisar dados do Inquérito Nacional de Alimentação (INA), verificaram um consumo insuficiente de frutas, verduras e legumes, aproximadamente um terço das recomendações do Guia Alimentar para a População Brasileira. Closs et al..$^{24}$, ao investigar o índice de alimentação saudável em idosos atendidos em um ambulatório de geriatria, observaram que $21 \%$ dos mesmos apresentavam inadequação no consumo de frutas. Viebig et al. ${ }^{17}$, ao estudar idosos de baixa renda de São Paulo-SP, apontaram que banana, laranja e mexerica foram as frutas mais consumidas diariamente. Apenas $8 \%$ dos idosos referiram consumo diário de maçã, pera, mamão e suco de laranja. Mais de $75 \%$ dos idosos nunca consumiam 10 das 17 frutas investigadas através de um questionário de frequência alimentar (caju, acerola, abacate, morango, pêssego, figo, abacaxi, uvas, melão e melancia). Carlos et al. ${ }^{21}$ verificaram que banana e laranja eram frutas frequentemente consumidas por idosos residentes no município de São Paulo e que não houve diferença significativa quanto ao tamanho das porções médias entre os sexos. Os autores ressaltaram que foi observada maior variedade no consumo de frutas pelos idosos.

\section{Leguminosas}

As leguminosas, de acordo com a ANVISA ${ }^{13}$, são os grãos produzidos em vagens, como feijões, lentilha, grão-de-bico, soja, ervilha, fava e amendoim. São boas fontes de proteína, amido, fibra solúvel (pectinas, gomas, mucilagens) e fibra insolúvel, fitoquímicos, óleos, minerais e vitaminas ${ }^{25}$.

O consumo a longo prazo em pequenas quantidades regulares de grãos de leguminosas auxilia na prevenção de dislipidemias, Diabete Mellitus, redução de triglicerídeos e colesterol, quando consumidos inteiros ou na forma de óleo (não aquecidos). Apresentam, também, um grande potencial de redução na mortalidade por doenças cardiovasculares e síndrome metabólica ${ }^{25}$, além de apresentar efeitos favoráveis na redução da pressão arterial e do peso corporal|26,27,28.

Dados oriundos da POF 2009-2010 mostraram uma redução do consumo desses alimentos pela população em geral, porém uma manutenção na população idosa, o que pode ser considerado positivo em relação às faixas etárias mais jovens ${ }^{20}$.

O feijão é um dos mais importantes componentes da dieta alimentar brasileira ${ }^{29}$. Feijão e arroz correspondem a quase um quarto da alimentação do brasileiro ${ }^{5}$. A preparação típica brasileira de feijão com arroz é uma combinação alimentar saudável e completa em proteínas ${ }^{8}$. Porém, se observa uma tendência de queda no seu consumo pela população geral, em prol de alimentos industrializados e menos saudáveis. Entre 1974 e 2003, a participação relativa de feijão e outras leguminosas no total energético da alimentação caiu em $31 \%^{8}$.

O feijão foi o segundo alimento mais consumido por adultos e idosos do município de São Paulo, perdendo apenas para o consumo de arroz ${ }^{8,20,21}$. Na comparação por sexo, os homens consomem maiores porções de feijão do que as mulheres ${ }^{21}$. Entre idosos do sexo masculino a porção de feijão foi estatisticamente maior entre os eutróficos ${ }^{21}$.

No estudo conduzido por Closs et al. ${ }^{24}$, foi observado que as leguminosas, em conjunto com carnes e ovos, apresentaram o maior percentual de inadequação no consumo por idosos do Rio Grande do Sul.

\section{Leite e derivados}

O leite é um alimento versátil, pois apresenta uma grande diversidade de derivados, como queijo, iogurte e está presente em inúmeros produtos da indústria alimentícia ${ }^{30}$.

O leite e seus derivados são alimentos essenciais para o desenvolvimento humano, pois são fontes de proteínas (aminoácidos essenciais e de alto valor biológico), gorduras e carboidratos (fonte eficaz de energia para idosos), vitaminas A e $D$, magnésio, cálcio, potássio e água ${ }^{31,32,33}$. Dentre esses nutrientes, destacam-se o cálcio e a vitamina $\mathrm{D}$, que são importantes na prevenção da osteoporose ${ }^{32}$, obesidade, redução do risco de Diabete Mellitus tipo 2, de hipertensão e de risco cadiovascular 32,34 .

A pirâmide adaptada para a população idosa americana preconiza a ingestão de três porções de leite e derivados por dia. Mas existem poucos estudos que avaliam esse consumo na população acima de 60 anos, especialmente no Brasil ${ }^{31}$.

A POF de 2008-2009, que analisou o consumo alimentar da população brasileira, mostrou que idosos apresentavam consumo insatisfatório de produtos lácteos. Também apontou uma queda de $40 \%$ no consumo de leite pela população geral desde a última pesquisa ${ }^{18}$.

Passanha et al. ${ }^{31}$ verificaram que, em idosos atendidos em uma unidade básica de saúde da zona oeste do município de São Paulo, o grupo com mais de 75 anos e as mulheres referiam maior consumo de leite. Os autores atribuíram este comportamento provavelmente ao fato de que estes grupos de idosos frequentam mais os serviços de saúde e recebem mais orientações nutricionais, ou tendência de morarem sozinhos e substituírem as refeições principais por lanches ${ }^{31}$. Contudo, a ingestão média verificada no estudo foi de um copo de leite ao dia, considerada insuficiente ${ }^{31}$.

Carlos et al. ${ }^{21}$, em idosos residentes no município de São Paulo, também observaram que o tamanho da porção média ingerida de leite era 30\% menor que o ideal. Vieira ${ }^{35}$, 
estudando os hábitos dietéticos de idosos do Rio Grande do Sul, encontrou que o consumo médio de lácteos foi inadequada e significativamente menor entre os homens ${ }^{35}$. Em relação à origem étnica, foco do estudo, foi constatado que os idosos do grupo étnico italiano referiram um consumo adequado de leite e derivados significativamente mais frequente que os idosos de origem multiétnica e alemã (73,6\%, 58\% e $50 \%$, respectivamente).

Alguns autores atribuem o baixo consumo de lácteos à difusão de resultados de estudos que indicam ser desnecessário o consumo na vida adulta e sobre a ocorrência de intolerância à lactose entre os idosos ${ }^{36,37}$. Entretanto, outros estudos desmistificam essas teorias, mostrando a ocorrência mínima desses efeitos e incentivando o consumo de leite em todas as fases da vida ${ }^{38}$.

\section{Carnes e ovos}

Carnes e ovos devem fazer parte de uma alimentação saudável e nutritiva. Segundo o Guia Alimentar para a População Brasileira ${ }^{8}$, os profissionais da saúde devem orientar o consumo de uma porção de carnes vermelhas, aves, peixes ou ovos por dia, pois são alimentos ricos em proteína e nutrientes essenciais, como vitaminas, minerais e ácidos graxos ${ }^{39}$. Este grupo é composto por alimentos fonte de proteínas de alto valor biológico pela disponibilidade em aminoácidos essenciais e pela digestibilidade dos mesmos ${ }^{39}$.

O controle da ingestão calórica total da dieta contribui para a utilização adequada da proteína, ou seja, a deficiência energética poderá agravar a deficiência proteica, fazendo com que os aminoácidos sejam desviados de sua função principal, a síntese proteica, para atender às necessidades energéticas do organismo ${ }^{40}$.

As carnes possuem uma alta biodisponibilidade de ferro, sendo este mineral fundamental ao organismo humano, por estar envolvido em algumas funções como: formação dos glóbulos vermelhos, transporte do oxigênio e de dióxido de carbono, respiração celular, síntese de colágeno, remoção de lipídios do sangue, produção de anticorpos, entre outras $^{41}$.

O Ministério da Saúde ${ }^{10}$ recomenda: (1) retirar a gordura aparente das carnes e a pele das aves (ricos em ácidos graxos saturados e colesterol) ${ }^{42}$, antes da preparação, com a finalidade de tornar esses alimentos mais saudáveis; (2) con-

sumir peixe fresco pelo menos duas vezes por semana, sugerindo que, tanto os de água doce como os de água salgada, são saudáveis; (3) o consumo, pelo menos, uma vez por semana, de vísceras e miúdos, como o fígado bovino, moela, coração de galinha, entre outros.

Segundo o Guia Alimentar para a População Brasileira ${ }^{8}$, tem-se observado um aumento da participação das carnes no total de calorias determinada pela aquisição alimentar domiciliar entre 1974-2003.

Em relação ao consumo de peixes, dados da POF 20082009 apontam que indivíduos da região norte do Brasil consomem peixe habitualmente, representando o dobro do consumo por parte dos nordestinos e sete vezes mais que aqueles das demais regiões ${ }^{11,18}$.

Em um estudo onde foi avaliado o índice de alimentação saudável de idosos sulbrasileiros, a frequência de inadequação do consumo de carnes e ovos foi de $47,8 \%$. Apenas $18,8 \%$ de dos idosos apresentaram o escore máximo de adequação ${ }^{24}$. Em estudo que analisou o consumo de alimentos de 364 idosos de três diferentes etnias, do Rio Grande do Sul, os indivíduos do grupo multiétnico consumiam mais porções/ dia de aves e os italianos de pescados. Os idosos de origem italiana consumiam menos porções/dia de carne vermelha. Já o consumo de ovos não diferiu entre os grupos étnicos. Em relação ao sexo, somente o consumo de aves foi significativamente maior entre as mulheres. Contudo, em relação à frequência de consumo diário de carnes em geral, a mesma foi inferior a duas vezes/dia em todos grupos étnicos avaliados ${ }^{35}$.

Problemas orais e dentais, bem como o menor poder aquisitivo desta população devido à aposentadoria, podem contribuir para o menor consumo de carne pelos idosos $^{36}$. O consumo de ovos, por sua vez, tem diminuído consideravelmente no Brasil, provavelmente devido ao fato de que seu consumo foi substituído pela compra de alimentos industrializados, consequentemente diminuindo o uso de ovos em preparações caseiras ${ }^{8}$.

\section{Açúcares e doces}

Açúcares é o termo utilizado para designar os carboidratos, sendo que os açúcares simples são do tipo monossacarídeo e dissacarídeo. Estes são usados para adoçar e melhorar o sabor de alimentos e bebidas, bem como na sua conservação. Os açúcares simples possuem como função a produção de energia; entretanto, não são essenciais para o organismo humano, pois a energia necessária pode ser adquirida pelos alimentos fontes de carboidratos complexos ${ }^{43}$.

Os alimentos-fonte do grupo dos açúcares e doces são os biscoitos, chocolates, doces em geral, refrigerantes, sorvetes, frutas cristalizadas, dentre outras preparações nas quais são adicionados os açúcares simples como um dos principais ingredientes, em termos quantitativos ${ }^{43}$. O consumo frequente e excessivo deste grupo alimentar pode aumentar a prevalência de sobrepeso/obesidade e de intolerância à glicose/Diabetes mellitus, que são considerados fatores de risco para doenças crônicas não transmissíveis como as doenças cardiovasculares ${ }^{10,44}$. 
O Ministério da Saúde recomenda evitar refrigerantes e sucos industrializados, bolos, biscoitos e outras guloseimas como regra da alimentação. Apenas uma porção deste grupo de alimentos pode ser consumida por dia. Deve-se, em contrapartida, valorizar o sabor natural dos alimentos e das bebidas evitando ou reduzindo o açúcar adicionado a eles ${ }^{10}$.

Dados da POF 2002-2003 ${ }^{18}$ apontam que os açúcares e refrigerantes tiveram participação relativa de $13,4 \%$ no total de calorias determinado pela aquisição alimentar domiciliar Levy-Costa ${ }^{19}$. A menor participação relativa do açúcar/refrigerante no total das calorias foi na região Norte $(10,8 \%)$ e a maior participação foi na região Sudeste $(14,2 \%)$. Os pesquisadores observaram que a classe de maiores rendimentos apresentava um consumo de açúcar 50\% inferior ao observado na classe de menores rendimentos. Já em relação aos refrigerantes, foi observado o contrário (o consumo foi cinco vezes maior na classe de maiores rendimentos do que na classe de menores rendimentos). Finalmente, concluíram que o teor de açúcar na dieta do brasileiro superou o limite máximo de $10 \%$ das calorias ingeridas em todo o País ${ }^{19}$.

Bueno et al. ${ }^{45}$, em um inquérito populacional domiciliar, realizado com adultos e idosos da cidade de São Paulo, mostraram que $27,1 \%$ dos idosos apresentaram uma ingestão de açúcar adicionado maior que $10 \%$ da ingestão de energia. Contudo, esta frequência foi significativamente menor que nos adultos $(38,1 \%)$. Os pesquisadores observaram que mais de $50 \%$ dos açúcares adicionados eram provenientes de refrigerante e de açúcar de mesa tanto nos homens quanto nas mulheres e tanto nos adultos quanto nos idosos. Porém, a principal fonte destes açúcares foi o refrigerante entre os adultos e o açúcar de mesa entre os idosos. A média do consumo dos açúcares adicionados foi maior entre as mulheres ${ }^{45}$.

\section{Gorduras e óleos}

A gordura alimentar é constituída por triglicerídeos (98\%), que são compostos de glicerol e ácidos graxos (saturados, monoinsaturados, poli-insaturados ou trans), sendo o restante constituído por colesterol ${ }^{46}$. A quantidade total de gorduras da dieta e os tipos de ácidos graxos são importantes para determinar o potencial aterogênico das gorduras ${ }^{46}$.

Os ácidos graxos saturados elevam o colesterol sanguíneo, e podem ainda promover a elevação dos triglicerídeos e do LDL-c ${ }^{47}$. Os ácidos graxos insaturados são classificados em duas categorias principais: poli-insaturados (ômega-6 e ômega-3) e monoinsaturados (ômega-9). Os ácidos graxos ômega-6 (óleos vegetais de soja, milho e girassol) reduzem o colesterol total e o LDL-colesterol, mas possuem o inconveniente de induzir maior oxidação lipídica e diminuir o HDL (High Density Lipoprotein) colesterol plasmático, quando utilizados em grande quantidade. Os ácidos graxos ômega-3, encontrados nos vegetais (soja, canola e linhaça) e em peixes de águas frias (cavala, sardinha, salmão e arenque) promovem redução dos triglicerídeos (TG) plasmáticos, podendo ainda exercer efeitos como redução da viscosidade do sangue, maior relaxamento do endotélio e também efeito antiarrítmicos. Os ácidos graxos monoinsaturados (óleo de oliva, óleo de canola, azeitona, abacate e oleaginosas) exercem o mesmo efeito sobre a colesterolemia; entretanto, não diminuem o HDL-c e não provocam a oxidação lipídica ${ }^{42}$.

O consumo de ácidos graxos trans aumenta o LDL-c e os TG e reduz a fração do HDL-c, devendo ser diminuído. São fontes deste ácido graxo, óleos e gorduras hidrogenadas, margarinas duras e shortenings (gorduras industriais presentes em sorvetes, chocolates, produtos de padaria, salgadinhos tipo chips, molhos para saladas, maionese, cremes para sobremesas e óleos para fritura industrial) e, em menor quantidade, produtos lácteos e carnes bovinas e caprinas ${ }^{48}$.

A ingestão inadequada, em quantidade e frequência, de alimentos fonte de gorduras pode aumentar a densidade energética da dieta e, como consequência, ser um fator para o aparecimento da obesidade, podendo ocasionar ainda Diabetes mellitus tipo 2, principalmente relacionado à obesidade abdominal e à resistência à insulina ${ }^{47}$.

Segundo a IV Diretriz Brasileira sobre Dislipidemias e Prevenção da Aterosclerose ${ }^{42}$, deve-se reduzir o consumo dos alimentos de origem animal ricos em colesterol (vísceras, leite integral e seus derivados, embutidos, frios, pele de aves e frutos do mar) e ácidos graxos saturados (carnes gordurosas, leite integral e derivados), polpa e leite de coco e de alguns óleos vegetais como o de dendê.

O Ministério da Saúde ${ }^{10}$ recomenda, para os idosos, o consumo de, no máximo, uma porção por dia de óleos vegetais (canola, girassol, milho, algodão e soja), azeite, manteiga ou margarina; uma lata de óleo por mês é suficiente para uma família de quatro pessoas. Usar azeite de oliva, sem exagerar na quantidade, para temperar as saladas; preparar os alimentos utilizando pouca quantidade de óleo, preferindo assados, cozidos, ensopados e grelhados, e evitar cozinhar com margarina, gordura vegetal ou manteiga; preferir as margarinas sem gorduras trans ou marcas com menor quantidade desse ingrediente; retirar a gordura aparente das carnes e a pele das aves antes da preparação e reduzir o consumo de embutidos (salsicha, linguiça, salame, presunto e mortadela), queijos amarelos, frituras e salgadinhos, para, no máximo, uma vez por semana.

Um estudo realizado com o objetivo de verificar a adequação da ingestão de nutrientes, com 550 participantes do município de Bambuí/MG, verificou que 39,3\% dos 
idosos apresentaram inadequação das frações lipídicas, sendo que $35,7 \%$ informaram consumo excessivo de ácidos graxos saturados ${ }^{49}$.

Outra pesquisa realizada com 130 idosas, no Rio Grande do Sul, com o objetivo de avaliar o perfil lipídico da dieta e sua correlação com os fatores de risco para doenças cardiovasculares, também verificou inadequação na proporção de gorduras saturadas e insaturadas ${ }^{50}$.

No estudo de Closs et al. ${ }^{24}$, foi verificado que o colesterol total foi o componente do índice de alimentação saudável com maior percentual de adequação (68.3\%). A frequência de inadequação do consumo de colesterol total e de gordura saturada foi de apenas $0,5 \%$. Cabe destacar que os idosos avaliados encontravam-se em primeiro atendimento em um serviço terciário especializado (ambulatório de geriatria).

Em relação à ingestão de ácidos graxos, Vieira ${ }^{35}$, que estudou idosos da comunidade, observou inadequação somente para os ácidos graxos saturados (AGS). Os idosos masculinos apresentaram ingestão de AGS representando 9,37\% do valor calórico total e as idosas 10,41\%. A IV Diretriz Brasileira sobre Dislipidemias e Prevenção da Aterosclerose ${ }^{42}$ recomenda a ingestão de AGS de até $7 \%$ do valor calórico total da dieta. Em relação ao colesterol e aos lipídios, a pesquisadora observou adequação da ingestão.

\section{Água}

A água representa aproximadamente $50 \%$ do peso corporal dos indivíduos idosos ${ }^{51}$. A hidratação deficiente nesta fase da vida pode ser ocasionada por vários fatores: utilização de medicamentos (como laxantes e diuréticos); ingestão de líquidos reduzida devido à menor sensação de sede; acesso limitado à água por dificuldade de locomoção ou motora ou dependência física; alterações na função renal associadas ao envelhecimento; presença de febre ou diarreia; viver em locais de temperatura elevada e prática de exercício físico ${ }^{32}$.

A água é considerada um ingrediente vital e sua ingestão adequada é essencial devido às diversas funções que desempenha no organismo, tais como: manutenção do volume plasmático, controle da temperatura corporal, transporte de nutrientes, participação no processo digestório, respiratório, cardiovascular e renal ${ }^{52}$.

A ingestão adequada de água total para mulheres e homens acima de 51 anos é 3,7 litros/dia e 2,7 litros/dia respectivamente, podendo ser composta por bebidas (incluindo chá, café, sucos, refrigerantes e água potável) e a água presente nos alimentos ${ }^{53}$. O Ministério da Saúde ${ }^{8}$ recomenda aos idosos a ingestão de pelo menos 2 litros (6 a 8 copos) de água por dia. Deve ser dada preferência ao consumo nos intervalos das refeições. Bebidas açucaradas como refrigerantes e sucos industrializados não devem substituir a água. Finalmente, a água utilizada para beber e preparar refeições, deverá ser tratada, fervida ou filtrada.

Um estudo com idosos residentes no interior do Rio Grande do Sul constatou um consumo de 5,7 copos de água e 9,1 copos de outros líquidos diariamente ${ }^{54}$.

\section{CONSIDERAÇÕES FINAIS}

As evidências apontam que o consumo dos alimentos integrantes dos grupos da pirâmide alimentar adaptada para a população idosa americana por idosos brasileiros, em geral, não está adequado. Somente os dados referentes ao consumo de gorduras mostraram-se controversos, apontando tanto adequação (em relação ao consumo de colesterol, gordura saturada, ácidos graxos monoinsaturados e ácidos graxos poli-insaturados) quanto inadequação (especialmente em relação ao consumo de ácidos graxos saturados).

Neste contexto, faz-se necessária a implementação de medidas efetivas que visem tanto orientar quanto promover uma alimentação saudável entre os idosos, para que este grupo etário da população possa vivenciar um envelhecimento ativo e bem sucedido.

\section{REFERÊNCIAS}

1. Beltrão KI, Camarano AA, Kanso S. Dinâmica populacional brasileira na virada do século XX. Instituto de pesquisa econômica aplicada (IPEA). Rio de Janeiro (RJ): IPEA; 2004. Texto para discussão 1034.

2. Veras R. Envelhecimento populacional contemporâneo- demandas, desafios e inovações. Rev Saude Publica. 2009;43(3):548-54. http:// dx.doi.org/10.1590/S0034-89102009000300020

3. Terra NL, El-Kik RM, Watte M, Vieira JMS, Marchi DSM, David CN, Souza CG, Teixeira AS. Alimentação saudável: é possivel ter uma alimentação equilibrada. In: Terra NL, El-Kik RM, Watte M, Vieira JMS, Marchi DSM, David CN, Souza CG, Teixeira AS, editores. A nutrição e as doenças geriátricas. Porto Alegre: EDIPUCRS; 2011. p. 11-20.

4. Brasil. Ministério da Saúde. Departamento de Atenção Básica. Caderno de atenção básica 19 - Envelhecimento e saúde da pessoa idosa. Brasília (DF): Ministério da Saúde; 2009. 36 p.

5. Brasil. Ministério da Saúde. Secretaria de Atenção à Saúde. Departamento de atenção Básica. Coordenação Geral de Alimentação e Nutrição. Guia alimentar para a população brasileira. Brasília (DF): Ministério da Saúde; 2014. 87 p.

6. Lanzillotti HS, Couto SRM, Afonso FM. Pirâmides alimentares: uma leitura semiótica. Rev Nutr. 2005;18(6):785-92. http://dx.doi. org/10.1590/S1415-52732005000600009

7. Lictenstein AH, Rasmussen H, Yu WW, Epstein SR, Russel RM. Modified MyPyramid for Older Adults. J Nutr. 2008;138:78-82.

8. Brasil. Ministério da Saúde. Secretaria de Atenção à Saúde. Departamento de Atenção Básica. Coordenação Geral de Alimentação e Nutrição. Guia alimentar para a população brasileira: promovendo a alimentação saudável. Brasilia (DF): Ministério da Saúde; 2008. 210 p. 
9. Mattos LL, Martins IS. Consumo de fibras aliamentares em população adulta. Rev Saude Publica. 2000;34(1):50-5. http:// dx.doi.org/10.1590/S0034-89102000000100010

10. Brasil. Ministério da Saúde. Secretaria de Atenção à Saúde. Departamento de atenção Básica. Alimentacao saudavel para a pessoa idosa: um manual para profissionais de saúde. Brasília (DF): Ministério da Saúde; 2009. 36 p.

11. Fisberg RM, Marchioni DM, Castro MA, Verly Junior E, Araújo MC, Bezerra IN, Pereira RA, Sichieri R. Ingestão inadequada de nutrientes na população de idosos do Brasil. Rev Saude Publica. 2013;47(1 Suppl):222S-30S. http://dx.doi.org/10.1590/S003489102013000200008

12. Malta MB, Papini SJ, Corrente JE. Avaliação da alimentação de idosos de município paulista: aplicação do IAS. Clín Saúde Colet. 2013;18 (2):377-84. http://dx.doi.org/10.1590/S1413-81232013000200009

13. Agência Nacional de Vigilância Sanitária. [capturado 2012 ago. 5]. Disponível em: www.anvisa.gov.br

15. Carvalho PGB, Machado CMM, Moretti CL, Fonseca MEN. Hortaliças como alimentos funcionais. Hort Bras. 2006;24(4):397404. http://dx.doi.org/10.1590/S0102-05362006000400001

16. Cerqueira FM, Medeiros MHG, Augusto O. Antioxidantes dietéticos controvérsias e perspectivas. Quim Nova. 2007;30(2):441-9. http:// dx.doi.org/10.1590/S0100-40422007000200036

17. Viebig RF, Pastor-Valero M, Scazufca M, Menezes PR. Consumo de frutas e hortaliças por idosos de baixa renda na cidade de São Paulo. Rev Saude Publica. 2009;43(5):806-13. http://dx.doi.org/10.1590/ S0034-89102009005000048

18. Instituto Brasileiro de Geografia e Estatísitica. Pesquisa de orçamentos familiares 2008-2009: análise do consumo alimentar pessoal do Brasil. Rio de Janeiro (RJ): IBGE; 2010. 150 p.

19 Levy-Costa RB, Sichieri R, Pontes NS, Monteiro CA. Disponibilidade domiciliar de alimentos no Brasil distribuição e evolução (19742003). Rev Saude Publica. 2005;39(4):530-40. http://dx.doi.org/ 10.1590/S0034-89102005000400003

20. Jaime PC, Monteiro CA. Fruit and vegetable intake by Brazilian adults, 2003. Cad Saúde Pública. 2005;21(Sup):519-24.

21. Carlos JV, Rolim S, Bueno MB, Fisberg RM. Porcionamento dos principais alimentos e preparações consumidos por adultos e idosos residentes no município de São Paulo. Rev Nutr. 2008;21(4): 383-91. http://dx.doi.org/10.1590/S1415-52732008000400002

23. Organização Pan-Americana da Saúde. Doenças crônicodegenerativas e obesidade: estratégia mundial sobre alimentação saudável, atividade física e saúde. Brasília (DF): OPAS; 2003. 60 p.

24. Closs VE, Feoli AMP, Gomes I, Schwanke CHA. Healthy eating index of eldely: description and association with energy, macronutrients and micronutrients intake. Arch Latinoam Nutr. 2014;64(1):34-41.

25. Martins JM, Bento OP. As leguminosas como alimentos funcionais: o caso das dislipidémias e das doenças cardiovasculares. Rev Ciências Agrárias. 2007;30(1):385-99.

26. Anderson JW, Major AW. Pulses and lipaemia, short- and long-term effect: potential in the prevention of cardiovascular disease. Br J Nutr. 2002;88(Suppl 3):S263-71. http://dx.doi.org/10.1079/BJN2002716

27. Madar Z, Stark AH. New legume sources as therapeutic agents. Br J Nutr. 2002;88(Suppl 3):S287-92. http://dx.doi.org/10.1079/ BJN2002719
28. Merritt JC. Metabolic syndrome: soybean foods and serum lipids. J Natl Med Assoc. 2004;96(8):1032-41.

29. Embrapa. Cultivo do Feijão da primeira e segunda safras na Região Sul de Minas Gerais 2005 [capturado 2015 jan. 08].

30. Souza DD. Consumo de produtos lácteos informais, um perigo para a saúde pública: estudo dos fatores relacionados a esse consumo no município de Jacareí-SP [dissertação]. São Paulo: USP; 2005.

31. Passanha A, Garcia HS, Cervato-Mancuso AM, Andrade SC, Vieira VL. Milk consumption profile in elderly people. J Human Growth Develop. 2011; 21(2):319-26.

32. Marucci MFN, Ferreira LS. Ações preventivas na terceira idade. In: Filho WJ, Gorzoni ML. Geriatria e Gerontologia: o que todos devem saber. São Paulo: Roca; 2008. p. 461-88.

33. Haraguchi FK, Abreu WC, Paula H. Proteínas do soro do leite: composição, propriedades nutricionais, aplicações no esporte e benefícios para a saúde humana. Rev Nutr. 2006;19(4):479-88. http://dx.doi.org/10.1590/S1415-52732006000400007

34. Martini LA, Wood RJ. Milk intake and the risk of type 2 diabetes mellitus, hypertension and prostate cancer. Arq Bras Endocrinol Metabol. 2009;53(5):688-94. http://dx.doi.org/10.1590/S000427302009000500021

35. Vieira JM. Hábitos Dietéticos y situación nutricional de personas de edad avanzada de Rio Grande do Sul (Brasil) de três etnias diferentes [tese]. Madrid: Universidad Complutense de Madrid; 2007.

36. Sachs A, Oliveira PA, Magnoni D. Riscos nutricionais na terceira idade. In: Magnoni D, Cukier C, Oliveira PA. Nutrição na terceira idade. São Paulo: Sarvier; 2005. p. 43-52.

37. Lanou AJ. Should dairy be recommended as part of a healthy vegetarian diet? Counterpoint. Am J Clin Nutr. 2009;89(5):1638S-42S. http:// dx.doi.org/10.3945/ajcn.2009.26736P

38. Weaver CM. Should dairy be recommended as part of a healthy vegetarian diet? Point Am J Clin Nutr. 2009;89(5):1634S-7S. http:// dx.doi.org/10.3945/ajen.2009.267360

39. Cozzolino SMF, Cominetti C, Bortoli MC. Grupo das carnes e ovos. In: Philippi ST. Pirâmide dos alimentos: fundamentos básicos da nutrição. Barueri (SP): Manole; 2008. p. 167-209.

40. Marucci MFN, Alves RP, Gomes MMBC. Nutrição em Gerontologia. In: Silva SMCS, Mura JDP. Tratado de alimentação, nutrição e dietoterapia. São Paulo (SP): Roca; 2010.

41. Martino NMB, Martino HSD. Biodisponibilidade de minerais. In: Silva SMCS, Mura JDP. Tratado de alimentação, nutrição e dietoterapia. São Paulo (SP): Roca; 2010.

42. Cardiologia SB. IV Diretriz brasileira sobre dislipidemias e prevenção de aterosclerose. Arq Bras Cardiol. 2007;88(1):2-19.

43. Philippi ST, Silva GV, Pimentel CVMB. Grupo dos açúcares e doces. In: Philippi ST. Pirâmide dos alimentos: fundamentos básicos da nutrição. Barueri (SP): Manole; 2008. p. 293-314.

44. World Health Organization. Global Strategy on Diet, Physical Activity and Health. Fifty-seventh World Health Assembly. Genebra: WHO; 2004.

45. Bueno MB, Marchioni DML, César CLG, Fisberg RR. Added sugars: consumption and associated factors among adults and the elderly. 
São Paulo, Brazil. Rev Bras Epidemiol. 2012;15(2):256-64. http:// dx.doi.org/10.1590/S1415-790X2012000200003

46. Lottenberg AMP, Buonacorso V. Gordura alimentar e a síndrome metabólica. In: Giacagli LR, Silva MER, Santos RF. Tratado de síndrome metabólica. São Paulo (SP): Roca; 2010. p. 653-67.

47. Santos KMO, Aquino RC. Grupo de óleos e gorduras. In: Philippi ST. Pirâmide dos Alimentos: Fundamentos básicos da nutrição. Barueri (SP): Manole; 2008. p. 241-92.

48. ADA. Evidence-Based Nutrition Principles and Recommendations for theTreatment and Prevention of Diabetes and Related Complications. Diabetes Care. 2002;25(1):202-12. http://dx.doi. org/10.2337/diacare.25.1.202

49. Lopes ACS, Caiaffa WT, Sichieri R, Mingoti SA, Lima-Costa MF. Consumo de nutrientes em adultos e idosos em estudo de base populacional: Projeto Bambuí. Cad Saude Publica. 2005;21(4): 1201-9. http://dx.doi.org/10.1590/S0102-311X2005000400022
50. Muller AR, Wichmann FMA, Ohlweiler ZNC. Perfil lipídico da dieta alimentar como fator de risco para doenças cardiovasculares em idosas ativas. Rev Bras Geriat Gerontol. 2007;10(2):179-89.

51. Kuczmarski MF, Kuczmarski RJ, Najjar M. Descriptive Anthropometric Reference Data for Older Americans. J Am Diet Assoc. 2000; 100(1):59-66. http://dx.doi.org/10.1016/S0002-8223(00)00021-3

52. Paternez ACAL, Aquino RC. Água e eletrólitos. In: Philippi ST. Pirâmide dos Alimentos: fundamentos básicos de nutrição. Barueri (SP): Manole; 2008. p. 315-40.

53. IOM. Dietary Reference Intakes for water, potassium, sodium, chloride and sulfate. In: Medicine lo, editor. Washington (DC): The National Academies Press; 2004.

54. Carvalho APL, Zanardo VPS. Consumo de água e outros líquidos em adultos e idosos residentes no município de Erechim - Rio Grande do Sul. Perspectiva. 2010;34(125):117-28. 